\title{
La educación religiosa en Costa Rica: Aportes desde la interculturalidad
} Religious education in Costa Rica: Contributions from Interculturality

\section{O ensino religioso na Costa Rica: contribuições a partir da Interculturalidade}

\author{
José Mario Méndez Méndez ${ }^{1}$ \\ Universidad Nacional
}

\begin{abstract}
Resumen
En Costa Rica se carece de una reflexión sólida sobre el estatuto curricular de la educación religiosa. Si somos un país constitucionalmente multicultural y pluriétnico, resulta necesario asumir la tarea de clarificar el aporte específico de la educación religiosa en el conjunto de la propuesta educativa nacional. Esta tarea implica diálogos y búsquedas en torno a los objetivos, el "objeto de estudio", los criterios metodológicos, las áreas temáticas a privilegiar, el perfil de la persona docente, los criterios para la evaluación de los aprendizajes y el diálogo con otros componentes curriculares del sistema educativo nacional. Ese trabajo busca ofrecer algunas pistas que, junto a otros aportes, pueden contribuir al replanteamiento curricular de la educación religiosa costarricense desde una perspectiva intercultural.
\end{abstract}

Palabras clave: Educación religiosa, currículo, interculturalidad.

\begin{abstract}
In Costa Rica there is a lack of solid reflection on the curricular status of religious education. In a constitutionally multicultural and multiethnic country like this, it becomes necessary to assume the task of clarifying the specific contribution of religious education in the whole of the national educational proposal. This task involves dialogues and searches around topics like objectives, the "object of study", methodological criteria, thematic areas to emphasize, the teacher profile, the criteria for learning evaluation and for dialogue with other curricular components of the national educational system. This work seeks to offer some clues that, along with other contributions, can contribute to the curricular rethinking of Costa Rican religious education from an intercultural perspective.
\end{abstract}

Keywords: Religious education, curriculum, interculturality.

1 Académico en la Escuela Ecuménica de Ciencias de la Religión - Universidad Nacional, Costa Rica. Doctor en Filosofía Iberoamericana por la Universidad Centroamericana José Simeón Cañas, El Salvador. Correo electrónico: jose.mendez.mendez@una.ac.cr / ORCID: https://orcid.org/0000-0002-3838-5298 


\begin{abstract}
Resumo
$\mathrm{Na}$ Costa Rica, faz falta uma reflexão sólida sobre a estrutura curricular do ensino religioso. Como somos um país multicultural e multiétnico constitucionalmente, será necessário assumir a tarefa de esclarecer a contribuição específica do ensino religioso em toda a proposta educacional nacional. Esta tarefa envolve diálogos e buscas em torno dos objetivos, do "objeto de estudo", dos critérios metodológicos, das áreas temáticas a serem privilegiadas, do perfil do docente, dos critérios de avaliação das aprendizagens e de diálogo com os outros componentes curriculares do sistema educacional nacional. Este artigo procura oferecer algumas pistas que, juntamente com outras contribuições, possam contribuir para o repensar curricular do ensino religioso na Costa Rica a partir de uma perspectiva intercultural.
\end{abstract}

Palavras chave: Ensino religioso, currículo, interculturalidade.

\section{Introducción}

En Costa Rica, el restablecimiento de la educación religiosa ocurrió en el año 1940. Desde la perspectiva curricular, es posible distinguir en ella al menos tres grandes etapas: la primera, desde dicho año hasta finales de la década de los 80. Se trata del período en el que la educación religiosa fue desarrollada desde un modelo catequístico. Durante este período, los programas de estudio tuvieron una base doctrinal cristiana y fueron elaborados con la colaboración de agentes pastorales de la iglesia católica.

El segundo período se desarrolló durante la década de los 80 y la primera mitad de la década de los 90 . En este, la educación religiosa trató de renunciar a su talante catequístico y comenzó a acoger modelos curriculares del Ministerio de Educación Pública, pero conservando objetivos y contenidos de matriz católica. Se trata de la sustitución del modelo catequístico por uno teológico.

El último período corresponde a la elaboración de los programas de 1996, que fueron revisados en el año 2005, y que son los que todavía se utilizan en la educación púbica costarricense. Se trata de programas que intentaron combinar su matriz cristiana-católica con opciones curriculares más recientes como las que se referían a la educación por competencias o a la transversalidad de temas como cultura ambiental para el desarrollo sostenible, educación integral de la sexualidad, educación para la salud y vivencia de los derechos humanos para la democracia y la paz ${ }^{2}$. En este período se prolonga el modelo teológico.

Durante estos 80 años no ha sido posible abandonar del todo el modelo catequístico, ni se han dado pasos relevantes hacia una educación religiosa

2 Ministerio de Educación Pública (MEP). Educación religiosa III ciclo. (San José: MEP, 2005), 2. 
con identidad propia. El hecho de que la Conferencia Episcopal de Costa Rica haya intervenido decididamente, tanto en la elaboración de los programas como en la formación y selección del personal docente, ha impedido que la educación se repiense críticamente y redefina su identidad en diálogo con el contexto, con las pedagogías y con las políticas curriculares del país.

En estas páginas se busca ofrecer algunas pistas que, junto a otros aportes, pueden contribuir al replanteamiento curricular de la Educación Religiosa costarricense desde una perspectiva intercultural.

\section{La transformación curricular en la educación costarricense}

Los componentes curriculares corresponden a áreas del conocimiento que están en función de las políticas educativas del Estado. Ellos son dinámicos y flexibles. No se los puede entender aislados, sino en diálogo y complementariedad. La educación religiosa es uno de los componentes curriculares de la educación costarricense.

En Costa Rica, la transformación curricular de los últimos años se fundamenta en la política curricular denominada Fundamentación pedagógica para la transformación curricular: educar para una nueva ciudadanía, publicada por el Viceministerio
Académico del Ministerio de Educación Pública. Allí se indica que la educación para una nueva ciudadanía se basa en los derechos humanos y considera la necesidad de asumir deberes ciudadanos. Además, allí se indica que:

los procesos educativos buscan, así, la formación de personas que se aceptan y se respetan a sí mismas, que respetan a las demás personas y al medio ambiente; dichos procesos se enfocan en hombres y mujeres que, en igualdad de condiciones, puedan desarrollar plenamente sus potencialidades. ${ }^{3}$

Según ese mismo documento, los tres pilares que conducen este proceso de transformación curricular son "la ciudadanía para el desarrollo sostenible, la ciudadanía planetaria con identidad nacional, y la ciudadanía virtual con equidad social"4. La tarea de transformación curricular, desde la perspectiva de la nueva ciudadanía, implica asumir importantes retos, como la formación continua de las personas que integran cada comunidad educativa, la mediación pedagógica adecuada para construir conocimientos, el fomento de ambientes de aprendizaje, diversos $\mathrm{y}$ enriquecidos, y la evaluación formativa y transformadora.

3 Viceministerio Académico. Educar para una nueva ciudadanía. (San José: MEP, 2017), 11.

4 Viceministerio Académico, Educar para una nueva ciudadanía, 14. 
En este documento se indica también que, para encaminar adecuadamente los procesos educativos orientados a la transformación curricular, se establece un diseño curricular basado en habilidades. Aquí se entiende que las habilidades están relacionadas con: "[...] la capacidad de las personas para solucionar problemas y realizar tareas diversas, dentro de una pluralidad de condiciones, ambientes y situaciones" 5 .

Se trata, entonces, de una transformación curricular basada en el desarrollo de habilidades que potencian la nueva ciudadanía. Estas habilidades abarcan cuatro dimensiones: a) Maneras de pensar: se refiere al desarrollo cognitivo de cada persona, por lo que implica las habilidades relacionadas con la generación de conocimiento, la resolución de problemas, la creatividad y la innovación; b) Formas de vivir en el mundo: es la dimensión que conlleva el desarrollo sociocultural, las interrelaciones que se tejen en la ciudadanía global con el arraigo pluricultural y la construcción de los proyectos de vida; c) Formas de relacionarse con otros: desarrollo de puentes que se tienden mediante la comunicación y la colaboración; d) Herramientas para integrarse al mundo: es la apropiación de las tecnologías digitales y otras formas de integración, así como

5 Viceministerio Académico, Educar para una nueva ciudadanía, 27. la atención que debe prestarse al manejo de la información. ${ }^{6}$.

Para cada una de esas habilidades, el documento citado recoge y sugiere una serie de indicadores desde los cuales se busca potenciar "[...] una educación inclusiva que se apoye en el respeto hacia la diversidad y hacia cada una de las particularidades que hacen al ser humano único y valioso" ". Ese es, en síntesis, el marco curricular desde el cual se ha desarrollado, en los últimos años, un proceso de revisión de los programas de las diversas disciplinas que existen en el sistema educativo costarricense. Hay que aclarar, sin embargo, que los programas de educación religiosa siguen sin ser transformados.

\section{La educación religiosa como componente curricular en Costa Rica}

La educación religiosa es, según los programas vigentes, una parte del currículo descrita como acción eclesial, civil y educativa (en ese orden). Como acción eclesial, se refiere a:

[...] una tarea evangelizadora, orientada especialmente hacia la persona, la sociedad y la cultura, para una situación histórica y social concreta. Ella está en relación e interdependencia

6 Viceministerio Académico, Educar para una nueva ciudadanía, 30.

7 Viceministerio Académico, Educar para una nueva ciudadanía, 32. 
con la Pastoral Educativa, tiene íntima vinculación con otras áreas pertenecientes a la Pastoral Profética y con la inculturación del Evangelio. ${ }^{8}$

Como acción civil, la educación religiosa costarricense "[...] asume y orienta la vida humana, social, cultural y ética de la nación, promueve el desarrollo humano, ético y trascendente de nuestro pueblo, con el fin de contribuir a la formación integral de la Persona y la sociedad desde la perspectiva cristiana" 9 .

Finalmente, como acción educativa, "[...] se apoya en la fe y en la vivencia cristiana, desde su planteamiento religioso y ético; uno de sus propósitos es facilitar a los educandos la construcción del aprendizaje en relación con el núcleo central del mensaje cristiano" ${ }^{10}$.

Las tres razones que, según los programas, justifican la educación religiosa, coinciden en la centralidad de lo que reiteradamente se denomina, perspectiva cristiana o visión cristiana. Según los programas vigentes, la educación religiosa, por ser una asignatura y componente del currículo, tiene objeto y razón, propósitos, contenido y metodología propios; se plantean "[...] contenidos de la fe católica y aprendizajes, que se distinguen en gran medida por su carácter axiológico, afectivo y

8 MEP, Educación religiosa III ciclo, 16.

9 MEP, Educación religiosa III ciclo, 16.

10 MEP, Educación religiosa III ciclo, 16.

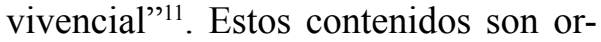
ganizados en tres grandes áreas:

- El cristiano en interacción consigo mismo y con su entorno familiar, social, cultural y religioso, en cuanto condición fundamental para su actuar como hijo de Dios.

- El cristiano en interacción con la creación y sus posibilidades para la ciencia y la tecnología, desde la perspectiva de su compromiso como colaborador en la obra de Dios.

- $\quad$ El cristiano en interacción con la comunidad eclesial como seguidor de Cristo y constructor de la civilización del amor. ${ }^{12}$

Al referirse al objeto y razón de la educación religiosa, se señala a la persona humana en interacción e interdependencia consigo mismo, con las demás personas, con la cultura, con la naturaleza, con el ambiente y con Dios, siempre desde sólidos principios cristianos.

En cuanto a los propósitos, el programa indica que con la educación religiosa se busca promover principios teóricos de carácter religioso y evangelizador, desde el núcleo esencial del mensaje cristiano y según la fe católica. También se pretende impulsar acciones educativas, religiosas y evangelizadoras como partes integrantes del

11 MEP, Educación religiosa III ciclo, 19-20.

12 MEP, Educación religiosa III ciclo, 21. 
proceso personal, social, cultural y ético. Finalmente, la Educación Religiosa se propone propiciar la valoración de la persona, la familia, la situación social, el entorno cultural, Jesús y la iglesia, así como promover una visión cristiana del ser humano, de la cultural y del mundo.

En cuanto a la metodología, se indica lo siguiente: "[...] el aprendizaje lo facilita mediante una metodología proveniente del dinamismo y riqueza del mensaje cristiano con sus exigencias éticas y de fe, así como por medio de una relación estrecha con la metodología y orientación científica de otras asignaturas del plan de estudios"13. Se trata de un enfoque metodológico que:

[...] involucra procesos deductivos e inductivos que facilitan al educando la construcción y reconstrucción del conocimiento con el fin de fortalecer la autonomía y la libertad, en función de su condición de protagonista en el proceso de transformación personal, social, cultural y espiritual respondiendo a la visión humanista, constructivista y académica estipulada. ${ }^{14}$

El Estado costarricense cuenta, además, con otros instrumentos en los cuales se suele fundamentar un currículo de educación religiosa de matriz cristiana. Uno de ellos es el Manual Descriptivo de Especialidades Docentes, de

13 MEP, Educación religiosa III ciclo, 20.

14 MEP, Educación religiosa III ciclo, 21. la Dirección General de Servicio Civil (DGSC), en el cual se estipula que:

La Educación Religiosa es un componente importante del currículo de la Educación General Básica y la Educación Diversificada de nuestro sistema educativo, busca que los alumnos asimilen y hagan propio el sistema de creencias, de juicios morales, de normas de conducta y de símbolos y ritos de la religión oficial de nuestro país. Esta se orienta de manera que los educandos participen de una educación integral y la vivencia de su compromiso como cristianos. ${ }^{15}$

Otro instrumento al que se hace referencia con frecuencia es la Ley Fundamental de Educación (1957) que, en sus artículos 3 (incisos b y c), 13 (inciso h) y 14 (inciso b), plantea como una de las finalidades de la educación costarricense el hecho de propiciar y cultivar los valores cristianos en el estudiantado.

Desde el año 2019, el Departamento de Educación Religiosa, a través de su sitio web oficial, describe así la Educación Religiosa costarricense:

La Educación Religiosa es una asignatura básica del plan de estudios del sistema educativo costarricense. Colabora con la formación integral del estudiantado, en cuanto enriquece los

15 Dirección General de Servicio Civil (DGSC). Religión, 19. http://www.dgsc.go.cr/ts_clase_docente/Especialidades\%20Docentes/Religion.pdf (consultada el 11 de mayo 2020). 
procesos humanos y sociales de la educación, mediante la interpretación religiosa, espiritual y trascendente de los aportes de las otras disciplinas.

Contribuye, acompaña, enriquece y fortalece con su visión humanista y trascendente, el proceso educativo costarricense en sus fines y propósitos. Se caracteriza por dos etapas: una confesional, y otra ecuménica, en el respeto a la diversidad, desde la propia identidad, para fomentar la sana convivencia desde la nueva ciudadanía. ${ }^{16}$

En esta redefinición hay un intento por combinar el proyecto de transformación curricular de nueva ciudadanía con el pronunciamiento 2023-2010 de la Sala Constitucional ${ }^{17}$. En este último, así como en el posterior acuerdo CSE 02-24-2017 del Consejo Superior de Educación, se solicitó al Ministerio de Educación Pública la elaboración de nuevos programas en dos etapas, una confesional, dirigida a la educación general básica; y otra ecuménica o ecléctica, para la educación diversificada.

16 Departamento de Educación Religiosa (DER). Propósito. http://www.ddc.mep.go.cr/educacion-religiosa. (consultada el 10 de mayo 2020).

17 Este pronunciamiento se refiere a la normativa que permitía contratar como docentes de Educación Religiosa solamente a quienes la Conferencia Episcopal otorgara la "misio canónica". La Sala anuló la normativa, sin embargo, el pronunciamiento es ambiguo y contradictorio, pues también pidió que la Educación Religiosa tuviese dos etapas, una de ellas confesional, con lo cual deja abierta la puerta a la intervención de la Conferencia Episcopal en la selección de Docentes.
Esa doble dirección en la que se mueve la transformación curricular actual de la Educación Religiosa costarricense posee vacíos, deja dudas y revela contradicciones: la etapa confesional, contradice el "por tanto" del pronunciamiento de la Sala Constitucional que declaró inconstitucional la normativa que permitía a la Conferencia Episcopal intervenir en la elección de las personas docentes de educación religiosa, así como los principios en los que tal pronunciamiento se apoya: el principio republicano y el de neutralidad religiosa del Estado costarricense en materia educativa. Por otro lado, ¿es la educación religiosa confesional tarea propia de un estado republicano? ¿Por qué asignarle al Estado tareas ecuménicas, propias de las iglesias cristianas? En el caso de una educación ecléctica, ¿quién y con qué criterios definirá qué es lo mejor de cada tradición religiosa? ¿En cuál de esas etapas se ubican las personas sin adhesión eclesial o sin pertenencia a alguna religión? ¿Cómo poner en diálogo esas dos etapas con la creciente diversidad de espiritualidades, creencias y convicciones de la población costarricense?

El siguiente cuadro resume la apuesta curricular presente en los programas de Educación Religiosa todavía vigentes: 


\section{Cuadro 1}

\begin{tabular}{|l|l|}
\hline Fundamentación & Razones eclesial, civil y educativa \\
\hline Vínculos & Pastoral educativa y profética, inculturación del Evangelio \\
\hline Objeto de estudio & $\begin{array}{l}\text { La persona humana y sus interacciones, desde sólidos } \\
\text { principios cristianos. }\end{array}$ \\
\hline Propósitos & $\begin{array}{l}\text { Promover principios teóricos de carácter religioso y } \\
\text { evangelizador; impulsar acciones educativas, religiosas y } \\
\text { evangelizadoras; propiciar la valoración de la persona, la } \\
\text { familia, la situación social, el entorno cultural, Jesús y la } \\
\text { Iglesia. }\end{array}$ \\
\hline Contenidos & $\begin{array}{l}\text { Los de la fe católica, así como aprendizajes que se distinguen } \\
\text { por su carácter axiológico, afectivo y vivencial: el cristiano } \\
\text { y sus interacciones consigo mismo, con su entorno, con la } \\
\text { creación y con la comunidad eclesial. }\end{array}$ \\
\hline Metodología & $\begin{array}{l}\text { Desde el dinamismo y riqueza del mensaje cristiano. } \\
\text { Relación con metodología de otras disciplinas. } \\
\text { Involucra procesos inductivos y deductivos. }\end{array}$ \\
\hline
\end{tabular}

Fuente: Elaboración propia

\section{Interculturalidad para una nueva ciudadanía: Aportes para una revisión curricular de la educación religiosa}

$\mathrm{Si}$ la transformación curricular promovida desde el Ministerio de Educación Pública gira en torno a una nueva ciudadanía, la interculturalidad es una perspectiva capaz de robustecer tal transformación. La perspectiva intercultural parece conveniente y necesaria por las siguientes razones:

Primero, porque Costa Rica es un estado pluricultural y multiétnico (Art. 1 de la Constitución). Lo ha sido siempre, pero ahora lo es "constitucionalmente". Tal reconocimiento debe tener consecuencias en todo el sistema educativo, en todos los componentes curriculares y, particularmente, en la educación religiosa.

Segundo, porque las diversas religiones y espiritualidades solo pueden expresarse, comunicarse y comprenderse a través de los lenguajes y recursos simbólicos de las diferentes culturas.

Tercero, porque la pedagogía intercultural implica ruptura con todas las formas de discriminación e intolerancia motivadas en la diversidad de culturas, etnias, nacionalidades, estilos de vida. La superación de esas formas de discriminación forma parte de la nueva ciudadanía. 
Cuarto, porque en Centroamérica la religión sigue siendo un elemento importante para construcción de identidades y de vínculos comunitarios.

Quinto, porque la educación intercultural implica reconocer la diversidad religiosa y cultural no como un problema sino como una posibilidad para el aprendizaje y para la convivencia.

Sexto, porque las religiones son patrimonio de la humanidad cuyo conocimiento es fundamental para el desarrollo de valores ciudadanos.

Sétimo, porque el voto 2023-2010 de la Sala Constitucional se fundamenta en los principios de separación entre religión y educación y neutralidad religiosa del Estado en el ámbito educativo: "[...] el Estado costarricense está llamado y obligado a respetar el principio de la neutralidad religiosa" (Sala Constitucional 2010, V). Tales principios refuerzan la perspectiva intercultural y la posibilidad de facilitar procesos educativos que promuevan el diálogo y la convivialidad para una nueva ciudadanía.

Pozzer y Wickert describen así una educación religiosa en perspectiva intercultural:

[...] no se limita a la socialización de conocimientos, sino que se comprende a sí misma como espacio de vivencia y experiencias de vida, intercambios y diálogos permanentes orientados al enriquecimiento de las identidades culturales religiosas y no religiosas. No se trata de fundir las diferencias, sino de un constante ejercicio de convivencia y de mutuo reconocimiento de las raíces culturales del otro y de sí mismo [...] Se busca el libre consentimiento y el respeto frente a la diversidad cultural del otro, con lo cual se construyen las bases de nuevas identidades más humanas y promotoras de buen-vivir. ${ }^{18}$

La perspectiva intercultural permite volver la mirada hacia otras visiones de mundo e ir más allá de los modelos catequístico y teológico para dar lugar a una Educación Religiosa capaz fortalecer la convivencia y la paz (nueva ciudadanía) a partir del reconocimiento de la diversidad de creencias, convicciones y tradiciones religiosas de quienes participan en los procesos educativos y del contexto en que ellos tienen lugar.

Por lo anterior, el modelo intercultural va más allá del no confesional. La no confesionalidad indica negación, mientras que la interculturalidad indica, de forma explícita, relacionalidad, conversación y convivialidad.

18 Adecir Pozzer y Tarcísio Wickert, "Ensino religioso intercultural: reflexões, diálogos e implicações curriculares", en Ensino Religioso na educação básica: fundamentos epistemológicos y curriculares, coords. Adecir Pozzer, Francisco Palheta, Leonel Piovenzana y María José Torres. (Florianópolis: Saberes em Diálogo, 2015), 92-93. 


\section{Hacia una propuesta de transformación curricular intercultural}

Comúnmente, a un componente curricular se le atribuyen elementos constitutivos como objeto de estudio, propósitos, contenido, metodología, evaluación del proceso enseñanza-aprendizaje, medios educativos, materiales, entre otros. Si tiene tales elementos se dice que posee autonomía epistemológica, la cual le otorga identidad propia y justifica, al menos en parte, su presencia en el sistema educativo. Siguiendo esa lógica, se propone a continuación un cuadro guía para la revisión y transformación curricular de la educación religiosa costarricense.

\section{Cuadro 2}

\begin{tabular}{|c|c|}
\hline Elementos curriculares & ¿A qué preguntas se quiere responder? \\
\hline Fundamentación & $\begin{array}{l}\text { ¿Cuáles son las bases legales y jurídicas de la educación } \\
\text { religiosa costarricense? ¿En qué instrumentos se apoya la } \\
\text { transformación curricular de la Educación Religiosa en Costa } \\
\text { Rica? ¿Es posible privilegiar algunos? }\end{array}$ \\
\hline El papel de Estado & $\begin{array}{l}\text { En materia de religión, ¿cuál es el papel de los estados } \\
\text { republicanos? ¿Corresponde a los estados educar desde } \\
\text { una única tradición religiosa en un contexto de diversidad } \\
\text { religiosa? }\end{array}$ \\
\hline $\begin{array}{l}\text { Los espacios } \\
\text { educativos }\end{array}$ & $\begin{array}{l}\text { ¿Los espacios de educación pública son adecuados para } \\
\text { transmitir doctrinas de una o más tradiciones religiosas? } \\
\text { ¿O son más bien lugares privilegiados para promover el } \\
\text { conocimiento de la diversidad cultural y religiosa? }\end{array}$ \\
\hline Sujetos & $\begin{array}{l}\text { ¿Quiénes son las personas aprendientes, protagonistas de los } \\
\text { procesos educativos en el ámbito de la educación religiosa? }\end{array}$ \\
\hline El contexto & $\begin{array}{l}\text { ¿El contexto en que se desarrollan los procesos educativos } \\
\text { contribuye a visibilizar la diversidad de culturas, creencias y } \\
\text { espiritualidades de las personas y de las comunidades? }\end{array}$ \\
\hline Delimitación & $\begin{array}{l}\text { ¿A qué hace referencia la educación religiosa? ¿Tiene que ver } \\
\text { solo con las religiones, o se interesa sobre todo de lo religioso } \\
\text { y de la religiosidad? } \\
\text { ¿Las distintas espiritualidades, creencias y convicciones } \\
\text { pueden ser incluidas en el ámbito de la educación religiosa? }\end{array}$ \\
\hline Propósitos & $\begin{array}{l}\text { ¿Qué queremos lograr a través de los procesos educativos que } \\
\text { serán promovidos en el campo de la educación religiosa? }\end{array}$ \\
\hline Epistemetodología & $\begin{array}{l}\text { ¿Qué tipo de conocimiento se produce desde la educación } \\
\text { religiosa? ¿Qué tipo de saberes se privilegian? ¿Cómo se } \\
\text { aprende en la educación religiosa? }\end{array}$ \\
\hline
\end{tabular}




\begin{tabular}{|l|l|}
\hline Bases disciplinarias & $\begin{array}{l}\text { ¿Cuáles ciencias o áreas de conocimiento fundamentan } \\
\text { a la educación religiosa? ¿Cuáles ciencias o áreas de } \\
\text { conocimiento contribuyen a visibilizar la diversidad religiosa } \\
\text { del contexto en que acontecen los procesos educativos? }\end{array}$ \\
\hline Contenidos & $\begin{array}{l}\text { ¿Qué se aprende desde la educación religiosa? ¿Qué relación } \\
\text { tienen esos contenidos con la vida y con la realidad? }\end{array}$ \\
\hline Evaluación & $\begin{array}{l}\text { ¿Para qué evaluar en la educación religiosa? ¿Qué se pretende } \\
\text { evaluar? ¿Qué criterios y estrategias de evaluación van a ser } \\
\text { privilegiadas? }\end{array}$ \\
\hline $\begin{array}{l}\text { Diálogo con otros } \\
\text { componentes } \\
\text { curriculares }\end{array}$ & $\begin{array}{l}\text { ¿Cómo se establece, en los espacios educativos, el diálogo } \\
\text { entre distintos saberes? ¿Qué áreas de conocimiento } \\
\text { interpelan a la educación religiosa? ¿Qué interpelaciones tiene } \\
\text { la educación religiosa para las otras disciplinas? }\end{array}$ \\
\hline
\end{tabular}

Fuente: Elaboración propia

A partir de las anteriores interrogantes, se ofrecen a continuación algunas sugerencias para el diálogo en torno a la urgente necesidad de transformar el currículo de educación religiosa costarricense.

Fundamentación: El principal fundamento legal de la educación religiosa es el artículo 1 de la Constitución Política, el cual, desde el año 2014, describe al Estado costarricense como multiétnico y pluricultural. Esa pluralidad cultural incluye la diversidad religiosa, pues las distintas tradiciones religiosas, con sus propias diversidades internas, son también expresiones de las culturas en que fueron gestadas o de aquellas en las que se expandieron o fueron implantadas.

El segundo soporte imprescindible es el documento Fundamentación pedagógica de la transformación curricular $^{19}$, desde el cual se conduce toda la revisión curricular costarricense actual, en todos los componentes curriculares y a partir del desarrollo de habilidades para una nueva ciudadanía. La educación religiosa puede contribuir a la formación de una nueva ciudadanía porque "... la educación del ciudadano es un proceso complejo que incluye múltiples elementos, entre ellos el religioso, el cual es un dato antropológico y social siempre presente en la historia de la humanidad"20

Es importante tomar en cuenta el Pronunciamiento 2023-2010 de la Sala Constitucional, sobre todo el "por tanto", con el cual se anula la normativa que permitía a la Conferencia Episcopal Costarricense participar en el

19 Viceministerio Académico, Educar para una nueva ciudadanía.

20 João Passos, Ensino religioso: Construção de uma proposta. (São Paulo: Paulinas, 2007), 33. 
nombramiento de las personas docentes de educación religiosa. Igualmente es necesario tener presente siempre el principio republicano en el que se basa dicho pronunciamiento. A ese principio "es consustancial la secularización de la esfera pública -a la que pertenece el sector educativo- $y$, por consiguiente, el respeto de la libertad religiosa y de la neutralidad confesional del Estado en esa órbita” ${ }^{\prime 21}$.

En cambio, los artículos 3 (inciso b y c), 13 (inciso h) y 14 (inciso b) de la Ley Fundamental de Educación -en los que se plantea que la educación costarricense debe propiciar y cultivar los valores cristianos en el estudiantado- deberían ser dejados de lado, pues, por haber sido formulados en 1957, están en conflicto con el artículo 1 de la Constitución Política, con el principio de neutralidad religiosa del Estado Costarricense en materia educativa, así como con convenios internacionales suscritos por Costa Rica como la Convención Interamericana de Derechos Humanos, en la cual se indica que:

... toda persona tiene derecho a la libertad de conciencia y de religión. Este derecho implica la libertad de conservar su religión o sus creencias, o de cambiar de religión o de creencias... nadie puede ser objeto de medidas restrictivas que puedan menoscabar la libertad de conservar su

21 Pronunciamiento 2023. (San José: Sala Constitucional, 2010), VI. religión o sus creencias o de cambiar de religión o de creencia. ${ }^{22}$

El papel del Estado: la enseñanza de una religión no es tarea que competa a un estado republicano. Es, más bien, tarea de las iglesias, de los grupos religiosos y de las familias. El principio de neutralidad religiosa del Estado costarricense en materia educativa, el cual fundamenta el voto 2023-2010 de la Sala Constitucional (VI), implica que la educación costarricense financiada por el Estado no puede ser utilizada para difundir enseñanzas de una determinada iglesia o grupo religioso.

Tampoco compete al Estado costarricense realizar procesos educativos de carácter ecuménico. El ecumenismo (entendido como diálogo entre diferentes cristianismos) es tarea y responsabilidad propia de las iglesias cristianas. Al Estado le corresponde, fundamentalmente, asegurar que exista libertad religiosa, libertad de culto, reconocimiento y respeto frente a la diversidad de creencias. El Estado garantiza que toda persona pueda creer, dejar de creer, cambiar de creencia y expresar sus creencias. El Estado es responsable de que nadie sufra discriminación por sus creencias. Por otro lado, toca también al Estado impedir que las iglesias y grupos religiosos utilicen a las instituciones públicas para fines proselitistas.

22 Convención Interamericana de Derechos Humanos (San José: 1969), art.12. 
Los espacios de educación formal: las escuelas y colegios pueden ser lugares adecuados para: a) la construcción de conocimientos relacionados con lo religioso en sus diversas expresiones, b) la convivencia en la diversidad y c) el fortalecimiento de una cultura de paz.

Una adecuada transformación curricular de la educación religiosa exige, por eso, tener presente el papel de las escuelas y colegios con respecto a la diversidad religiosa:

La escuela no es espacio para enseñar la religión o convicciones de una determinada confesionalidad, sino lugar para la construcción de conocimiento sobre la diversidad cultural religiosa ... Corresponde a los educadores y educandos reflexionar acerca de las diversas experiencias religiosas que les rodean; analizar el papel de los movimientos y tradiciones religiosas en la conformación y conservación de las diferentes culturas; comprender que cada sujeto o grupo social posee sus propias referencias para enfrentar los desafíos de la vida cotidiana y, sobre todo, eliminar toda forma de discriminación y prejuicio. ${ }^{23}$ (Cecchetti, Blanck, Schneider y Riske 2013, 35)

23 Elcio Cecchetti y otros, "Diversidade religiosa e direitos humanos: conhecer, respeitar e conviver". En Diversidade religiosa e direitos humanos: conhecer, respeitar e conviver, coords. Reinaldo Matias, Lilian Blanck, Lúcia Schneider, Elcio Cechhetti y Simone Riske (Blumenau: Edifurb, 2013), 35.
La tarea educativa de las escuelas y colegios con respecto a las tradiciones religiosas y espiritualidades, es educar en y para el reconocimiento de la diversidad, en y para el diálogo y la convivencia:

A la Escuela, en cuanto lugar de tránsito de culturas, no compete homogenizar la diversidad religiosa, sino garantizar la libertad religiosa, por medio de la igualdad de acceso al conocimiento de todas las culturas, tradiciones/grupos religiosos y no religiosos, promoviendo los derechos humanos. ${ }^{24}$

De esa manera, se contribuirá a la formación de una nueva ciudadanía, que se hará cargo de la diversidad en vez de invisibilizarla o negarla.

El contexto: todos los procesos educativos acontecen en un contexto concreto y en unas circunstancias que los condicionan. Para la educación religiosa es importante también que los procesos tengan lugar en diálogo con el contexto y las circunstancias. $\mathrm{Y}$ ese contexto, en el caso de Costa Rica, se caracteriza por una creciente diversidad de tradiciones religiosas y espiritualidades. El contexto también está marcado por una serie de conflictos: violencia de género, conflictividad social, polarización política y

24 Elcio Cecchetti y otros, "Diversidade religiosa e direitos humanos: conhecer, respeitar e conviver", 35 . 
discriminación, basados en la nacionalidad, en las preferencias sexuales o en el origen étnico, entre otros. Nada de eso puede ser ajeno a la educación religiosa, pues con mucha frecuencia tales conflictos se nutren de las creencias y/o de la adhesión a grupos religiosos.

El diálogo con el contexto, desde la educación religiosa, implica asumir posturas críticas y compromisos frente todas las formas de discriminación y frente a todo lo que amenaza a la vida humana y los ecosistemas.

Los sujetos: la educación involucra a estudiantes y docentes en una serie de interacciones orientadas al aprendizaje. Estos sujetos confluyen allí no por (debido a) sus creencias, pero sí con sus creencias y convicciones. La razón de la confluencia es el aprendizaje: se trata, por eso, de una interacción entre aprendientes que llevan consigo saberes, experiencias, memorias, creencias, convicciones. A otros lugares, algunas de estas personas llegan por (debido a) sus creencias, y llevando consigo los saberes y las preguntas generadas en las aulas.

La razón que justifica la educación religiosa no es la confesión religiosa de los sujetos, sino su condición de aprendientes. El derecho a la educación religiosa en los espacios educativos públicos no se basa en la confesión de una determinada fe. Se trata más bien del derecho que se fundamenta en "[...] el reconocimiento de la religiosidad y la religión como datos antropológicos y socioculturales que deben ser abordados junto a las demás disciplinas escolares por razones cognitivas y pedagógicas" ${ }^{25}$.

Delimitación: no existe un único modelo de educación religiosa. Para el caso de los espacios educativos públicos, es claro que un modelo confesional resultaría violento y discriminatorio. La educación religiosa no puede ser vista como la enseñanza de una religión. Passos distingue, de la siguiente manera, entre educación sobre, de y para la religión:

... la educación sobre la religión y de la religiosidad es una tarea de todos, comenzando por la escuela pública, lo que se distingue, evidentemente, de la educación para la religiosidad, que compete solamente a las confesiones religiosas dentro de sus comunidades. ${ }^{26}$

La educación religiosa tampoco se limita al estudio de los fenómenos religiosos, entendidos como "objeto de estudio" que deben ser conocidos. La separación entre sujetos y objetos de estudio, común en el mundo académico, suele nutrir prácticas educativas orientadas a dominar, controlar y utilizar el "objeto". En el caso de la

25 João Passos, Ensino religioso: Construção de uma proposta, 65.

26 João Passos, Ensino religioso: Construção de uma proposta, 46. 
educación religiosa, la tenencia de un objeto de estudio impide ver lo religioso como experiencia comunitaria que nos interpela, que habla. Por eso, más que "objeto de estudio", la educación religiosa tiene referentes: se refiere a la diversidad religiosa y a las consecuencias de tal diversidad para la convivencia de los seres humanos y para su forma de habitar la casa común.

Propósitos: la educación religiosa debe contribuir al desarrollo de habilidades para una nueva ciudadanía. Y la nueva ciudadanía no tendrá lugar mientras no aprendamos a reconocer lo religioso en su diversidad. Se trata entonces, de desarrollar aquellas habilidades que ayudan a reconocer como legítimas la diversidad de saberes, de experiencias, de creencias, de expresiones simbólicas y de textualidades religiosas que existen en el contexto.

Pero la nueva ciudadanía implicará también el desarrollo de habilidades para la convivencia y para la creación de una cultura de paz. Se busca "romper con relaciones de poder que encubren y naturalizan estereotipos, discriminaciones y prejuicios" 27 . Estas habilidades deben incluir las cuatro dimensiones sugeridas por el documento Fundamentación pedagógica para la transformación curricular: educar para una nue-

27 Elcio Cecchetti y otros, "Diversidade religiosa e direitos humanos: conhecer, respeitar e conviver", 35 . va ciudadanía, a saber: a) maneras de pensar; b) formas de vivir en el mundo; c) formas de relacionarse con otros y d) herramientas para integrarse al mundo.

Los propósitos muestran que ningún proyecto educativo es políticamente neutro, pues están atravesados (transversalidad) por opciones y modelos deseables de ciudadanía y de convivencia: se trata de formar ciudadanía crítica y responsable, capaz de acoger y vivir la diversidad religiosa como una oportunidad para aprender y convivir, y no como un problema; capaz de comprender los acontecimientos religiosos y la forma en que ellos inciden en las personas, en las comunidades, en el mundo.

Epistemetodología: ¿Tiene la educación religiosa una forma específica y propia de generar conocimiento? ¿Qué tipo de conocimiento genera? En la educación religiosa todo conocimiento debe ser el resultado del encuentro, de la conversación y de la interpelación. Eso implica romper con el adoctrinamiento y con métodos orientados a la transmisión de "verdades religiosas". Todas las personas aprendientes son portadores de saberes que, puestos en diálogo, generan nuevos saberes y nuevas formas de interacción. De tal manera, la educación religiosa produce un tipo de "conocimiento convivencial". Se construye conocimiento desarrollando $h a$ bilidades relacionadas con la escucha, el respeto mutuo, la valoración de las 
diferencias y la convivialidad. Los criterios de objetividad y verificabilidad, importantes en otras disciplinas, dejan paso aquí a criterios de relacionalidad, criticidad y alteridad.

El conocimiento se refiere a las tradiciones religiosas, a los mundos culturales que las produjeron, a las textualidades y simbolismos con que se expresan hoy. Y esa referencia busca ejercer dominio sobre unos temas, sino formular preguntas y provocar conversaciones que tienen que ver con búsquedas humanas, estilos de vida, interacciones que humanizan y mejores formas de estar en el mundo-en compañía.

Bases disciplinarias. Durante mucho tiempo, la educación religiosa tuvo a la teología como su principal aliada. Los planes de estudio de las universidades formadoras acentuaron las contribuciones teológicas, con lo cual se redujo la capacidad de las personas educadoras para abordar lo religioso desde otras perspectivas. Este tipo de educación religiosa es ubicada por Passos (2007) dentro de lo que él llama modelo teológico.

La diversidad cultural y religiosa de América Latina exige que, sin que se abandonen las teologías, sean acogidos los aportes de otros saberes en los procesos de formación de las personas docentes y en los caminos pedagógicos que estas acompañan en las instituciones educativas. Passos sugiere que actualmente el gran desafío de la Educación Religiosa es “... traducir los contenidos de las Ciencias de la Religión, con sus múltiples posibilidades de abordaje y de resultados, en contenidos que puedan ser incluidos en la Educación Religiosa"28.

Entre las disciplinas que pueden ayudar a visibilizar la diversidad religiosa están la antropología, las ciencias sociales, los estudios de la biblia y de otras textualidades sagradas, los estudios históricos sobre las religiones, las teologías, las ciencias que se interesan por el lenguaje simbólico de las tradiciones religiosas o por los vínculos entre religión-política y religión-economía, etc.

Contenidos: los contenidos también dependen del modelo de educación religiosa que se adopta. Desde modelos confesionales, multiconfesionales o multirreligiosos no es posible generar contenidos que den cuenta de toda la diversidad de creencias, espiritualidades y tradiciones religiosas del contexto costarricense. En este país, como en muchos otros, cada vez más personas deciden vivir sus "re-ligaciones" sin religiones y sin iglesias.

Desde una perspectiva intercultural, es urgente privilegiar áreas

28 João Passos, Ensino religioso: Construção de uma proposta, 34 . 
temáticas que contribuyan a visibilizar la diversidad de tradiciones religiosas y espiritualidades del país, de Latinoamérica y del mundo. El gran eje temático de la educación religiosa debería ser la diversidad de creencias, espiritualidades y tradiciones religiosas. Y si hay que priorizar algunas, deberían ser aquellas que han sido ignoradas desde los espacios educativos o deslegitimadas desde la cultura dominante: las tradiciones de los pueblos indígenas y afrolatinoamericanos. También existen diversos aspectos emergentes que deben ser considerados, como la comprensión de lo corpóreo y el lugar de lo diverso en las tradiciones religiosas, el papel de las religiones frente al cambio climático, la relación entre religión y poder, religión y género, entre otros.

La educación religiosa tiene el desafío de permitir que las personas aprendientes se vean interpeladas por aquello que en las distintas tradiciones religiosas contribuye a formar nueva ciudadanía: las invitaciones a la paz, a la justicia, a la misericordia, a la reconciliación, a la hospitalidad, etc.

Evaluación de los aprendizajes. La educación religiosa debería evaluar prioritariamente el desarrollo de habilidades orientadas a la construcción de nueva ciudadanía. Renuncia, por eso, a prácticas evaluativas memorísticas y violentas, para adoptar estrategias de evaluación que contribuyan al aprendizaje y que permitan realizar ajustes en las distintas mediaciones y propuestas didácticas.

Es importante evitar que la evaluación se convierta en una herramienta para homogenizar y para borrar las diferencias. Eso implica reconocer las habilidades que son fundamentales en cada contexto, generar procesos educativos orientados al desarrollo de tales habilidades y evaluar en función de ellas. La sustitución de prácticas de evaluación que causan temor por otras que faciliten el aprendizaje y la colaboración es importante en todas las áreas del conocimiento, no solo en la educación religiosa. La evaluación debería ser algo que se disfruta y se agradece.

Diálogo con otros componentes curriculares: La educación religiosa es una disciplina que necesita dialogar con otras áreas de conocimiento, pues ella no es la única que aborda el tema de las religiones y la religiosidad, pues existen disciplinas y áreas de conocimiento que se interesan, por ejemplo, del arte religioso, de la historia de las religiones, de habilidades para el ejercicio de la ciudadanía, de relatos creacionistas, etc. En la literatura latinoamericana, solo por mencionar un ejemplo, es posible identificar preocupaciones y relatos religiosos que pueden ayudar a la educación religiosa a dialogar con los discursos y las dinámicas religiosas del continente. 
Por otro lado, la educación religiosa debe estar atenta para reconocer las interpelaciones de otras áreas del saber, las invitaciones al diálogo y las oportunidades para el trabajo colaborativo interdisciplinario. El trabajo educativo interdisciplinario implica aprender a desarrollar y acompañar nuevas prácticas en las que la complementariedad de saberes no disuelve las especificidades, ni anula los aportes de cada disciplina para la formación de una nueva ciudadanía. Todas las disciplinas, no solo la educación religiosa, tienen la posibilidad de beneficiar el aprendizaje gracias al reconocimiento de las diferencias. Esa posibilidad es el punto de encuentro más importante de los distintos saberes.

\section{Bibliografía}

Cecchetti, Elcio y otros. 2013. Diversidade religiosa e direitos humanos: conhecer, respeitar e conviver. En Diversidade religiosa $e$ direitos humanos: conhecer, respeitar e conviver, coords. Reinaldo Matias, Lilian Blanck, Lúcia Schneider, Elcio Cechhetti y Simone Riske, 19-37. Blumenau: Edifurb,

Convención Interamericana de Derechos Humanos, 1969.

Ley Fundamental de Educación. Ver Ley fundamental de educación. http://www.pgrweb.go.cr/scij/ Busqueda/Normativa/Normas/ nrm texto completo.aspx?nValor $1=1 \& n \bar{V}$ alor2=31427, (consultada el 22 de abril 2020).

Departamento de Educación Religiosa. Ver_Departamento de Educación Religiosa. Propósito. http:// www.ddc.mep.go.cr/educacion-religiosa. (consultada el 10 de mayo 2020).

RELIGIÓN. Ver Dirección General de Servicio Civil. Religión. http:// www.dgsc.go.cr/ts clase docente/Especialidades $\%$ 20Docentes/ Religion.pdf (consultada el 11 de mayo 2020).

Ministerio de Educación pública. 2005. Educación religiosa III ciclo. San José: MEP.

Passos, João. 2007. Ensino religioso: Construção de uma proposta. São Paulo: Paulinas.

Pozzer, Adecir y Wickert, Tarcísio. 2015. Ensino religioso intercultural: reflexões, diálogos e implicações curriculares. En Ensino Religioso na educação básica: fundamentos epistemológicos y curriculares, coords. Adecir Pozzer, Francisco Palheta, Leonel Piovenzana y María José Torres. 89-101. Florianópolis: Saberes em Diálogo.

Sala Constitucional. 2010. Pronunciamiento 2023-2010. San José.

Viceministerio Académico. 2017. Educar para una nueva ciudadanía. San José: MEP. 